International Journal of Biology, Pharmacy and Allied Seiences (IJBPAS) 'A Bridge Betuen Caboratory and Qnendo'

WWW.ijbpas.com

\title{
MYTHODONTICS - KNOWLEDGE ON MYTHS REGARDING ORAL HEALTH AMONG GENERAL POPULATION: A QUESTIONNAIRE SURVEY
}

\author{
RAVINDRAN V ${ }^{1 *}$ AND SIVAKUMAR $\mathbf{N}^{2}$ \\ 1: Senior Lecturer, Department of Pedodontics, Saveetha Dental College \& Hospitals, Saveetha \\ University, Saveetha Institute of Medical and Technical Sciences, Chennai-600077
}

2: Saveetha Dental College \& Hospitals, Saveetha University, Saveetha Institute of Medical and Technical Sciences, Chennai- 600077

*Corresponding Author: E Mail: Dr. Vignesh Ravindran: vigneshr.sdc@saveetha.com Received $19^{\text {th }}$ March 2021; Revised 20 ${ }^{\text {th }}$ April. 2021; Accepted $19^{\text {th }}$ May 2021; Available online $1^{\text {st }}$ Aug. 2021

\section{https://doi.org/10.31032/IJBPAS/2021/10.8.1038}

\begin{abstract}
Myths have a strong influence in seeking treatment during illness. Understanding the myths and misconceptions about the disease is important in providing dental care. Not many studies had been done and not much data is available related to this subject. The aim of the present study was to assess the prevalence of myths regarding oral health, among out-patients attending a dental institute in Chennai. This study was a cross-sectional questionnaire survey. A close-ended questionnaire containing 21 questions related to the common myths in dentistry was shared among the patients attending the out-patient department using Google forms. The data collection was done during the month of January 2020. The obtained data were tabulated and processed using SPSS Software. Pearson's Chi-Square test was used to assess the responses for the questionnaire. The overall prevalence of myths regarding dental caries were $74.3 \%$, oral hygiene were $67.5 \%$, oral cancer were $55.6 \%$ and general dental aspects were $59.7 \%$. A higher percentage of males $(65 \%)$ believed the myth on dental treatment during pregnancy, higher percentage of adolescents $(66 \%)$ believed chocolates only caused cavities, while a majority of
\end{abstract}


early (53\%) and middle adulthood (49\%) groups knew it was a myth. A higher percentage of unemployed respondents $(60.8 \%)$ believed that having a little smoke or chewing tobacco at times wouldn't harm them. Within the limitations of the present study, there is a higher percentage of the population who still believes in myths related to dentistry. The myths were more common among people who were not graduates and also belonging to late adulthood and even adolescents.

\section{Key words: Dental Myths, Oral health, Beliefs.}

\section{INTRODUCTION}

Myths are defined as stories shared by a group of people, which are part of their cultural identity, having a strong influence in seeking treatment during illness [1]. Believing the myths does not necessarily arise in developing countries. Developed countries have their part in such myths either initiated in explanations of misunderstood verbal reports or directly propagated from ancestors who have immigrated to their adopted countries. Myths can be perpetuated and even morph into stories that are easily adapted to any purpose dealing with life and what life deals out. In certain instances, the myth even becomes a source of hilarity or on the dark side that points out major beliefs with differences between cultures [2].

Dental myths commonly emerge from false traditional beliefs and the absence of scientific knowledge. These myths are further embedded into the psyche of future generations over a period of time and thus, creates interference in the acknowledgement of scientific and contemporary dental treatment. A close look at folk-tales about deciduous teeth that exfoliates gives an idea about how myths vary around the globe. In modern Western culture, a character named 'tooth fairy' is said to give children a small gift in exchange for a deciduous tooth when it exfoliates. In Europe, eons ago, children used to throw exfoliated teeth in mouse holes, hoping that their permanent successor would be sharp. In northern Europe, the tradition of a "tooth fee," paid by parents when a child lost his/her first tooth was prevalent. In Asian countries (India, China, Japan, Korea, and Vietnam), children bury their upper teeth in the ground, believing that the successor teeth would be straight $[3,4]$.

Our department is passionate about child care, we have published numerous high quality articles in this domain over the past 3 years [5-23]. With this inspiration we planned to pursue our research to determine the prevalence of myths regarding oral 
health, among out-patients attending a dental institute in Chennai.

\section{MATERIAL AND METHODS:}

\section{Study design:}

This study was a cross-sectional questionnaire survey.

\section{Source of data:}

The source of data was primary. It was obtained from a survey, which included a questionnaire based on the myths and facts related to dentistry.

\section{Study population:}

The study population included all the patients attending the dental institute and those who were willing to participate in the study.

\section{Informed consent:}

The nature and purpose of the study was explained to the subjects and a signed consent was obtained. Patients who declined to sign the consent were excluded from the study.

\section{Sample size:}

Using SPSS Software Version $17^{\complement}$ keeping the power of the study at $95 \%$ and alpha error at 5\%, using G-power analysis, the sample size was decided from the data obtained from a similar previous study. The final sample size required for the main study was 500 patients.

\section{Sampling methodology:}

All the patients attending the dental institute who gave consent to participate were randomly included in the study until the required sample size was met.

\section{Questionnaire:}

A self-administered, pre-tested questionnaire in the vernacular language was given to the residents. It included 21 closeended questions. Five questions were based on the myths regarding dental caries, six questions were about the myths regarding oral hygiene, five questions were related to the myths regarding oral cancer and five questions were based on the myths regarding general dental aspects. Most myths were found from online sources $[3, \mathbf{4}, \mathbf{5}]$.

\section{Data collection:}

The data collection was done during the month of January 2020. The questionnaire was distributed to the patients in the out-patient department using the online platform, Google Forms. The obtained data were tabulated in MS Excel sheet and subjected to statistical analysis.

\section{Statistical analysis:}

The data were processed using Statistical Package for the Social Sciences (SPSS Software Version $17^{\circ}$ ).Pearson's ChiSquare test was used to assess the responses 
for the questionnaire. A ' $\mathrm{P}$ ' value $<0.05$ was considered statistically significant.

\section{RESULTS AND DISCUSSION:}

A total of 500 out-patients were randomly selected from different clinics of the dental institute. Among the respondents, $21.8 \%$ were adolescents, $26.8 \%$ were in early adulthood, $29.8 \%$ were in middle adulthood and $21.6 \%$ were in late adulthood. About $53.2 \%$ of respondents were males and $46.8 \%$ were females. Based on educational status, $26.8 \%$ completed schooling, $38.6 \%$ were undergraduates and $34.6 \%$ were postgraduates. Majority of the respondents were employed (65.8\%) (Table 1-4). The questionnaire was categorised under 4 topics : Myths based on dental caries, oral hygiene, oral cancer and general dental aspects.

Prevalence of myths regarding dental caries:

When questioned on the prevalence of myths related to dental caries, $54 \%$ of respondents believed that chocolate was the only cause of cavities, $60.8 \%$ of respondents believed that decay in milk teeth need not be treated as they were going to fall anyways, $61.4 \%$ of respondents believed that it was better to extract rather than saving a tooth, if any pain occurs due to decay, $61.6 \%$ of respondents believed that once a tooth was treated, decay stops in that tooth and $56.8 \%$ of respondents believed that there was no pain after Root Canal Treatment, so they don't need to place a crown [Table 5].

Prevalence of myths regarding oral hygiene:

When questioned on the prevalence of myths related to oral hygiene, $57 \%$ of respondents believed that the longer they brush, more brighter their teeth would become, $56.2 \%$ of respondents believed that use of hard bristles would clean their teeth better, $68.2 \%$ of respondents believed that brushing teeth using salt whitens the teeth, $66.4 \%$ of respondents believed that brick powder \& charcoal cleans teeth better than a toothpaste, $63.2 \%$ of respondents believed that when gums bleed, it was better not to brush \& floss the teeth and $54.6 \%$ of respondents believed that poor brushing was the only cause of bad breath [Table 6].

Prevalence of myths regarding oral cancer:

When questioned on the prevalence of myths related to oral cancer, $52.2 \%$ of respondents believed that chewing tobacco helps in maintaining good oral hygiene, $57.8 \%$ of respondents believed that smokeless tobacco was less harmful and a safe alternative to smoking, $53.8 \%$ of respondents believed that taking a puff of smoke or a chew of smokeless tobacco every 
now and then would not harm them, $61.6 \%$ of respondents believed that any relative with an oral cancer, then they were at a higher risk of getting cancer and $58.4 \%$ of respondents believed that a friend drinks, smokes and chews tobacco more than what I do, but still he doesn't have oral cancer and neither will they [Table 7].

\section{Prevalence of myths regarding general} dental aspects:

When questioned on the prevalence of myths related to general dental aspects, $54.6 \%$ of respondents believed that it was not required to visit a dentist unless a pain occurs in teeth, $60.8 \%$ of respondents believed that it was better to avoid dental treatment during pregnancy, $60 \%$ of respondents believed that extracting any upper teeth leads to loss of vision, $59.8 \%$ of respondents believed that extracted tooth needs no replacement with an artificial tooth and $65 \%$ of respondents believed that professional scaling leads to sensitivity, mobility in teeth and also creates gap between them [Table 8].

Comparison of the responses obtained from the questionnaire with the gender, age, educational status and employment status showed some associations which were statistically significant.

\section{Changes observed in relation to gender:}

On association of gender with response to the myth on dental treatment during pregnancy, a higher percentage of males $(65 \%)$ believed it, while the majority of females (44\%) knew it was a myth ( $p=$ 0.039) (Figure 1).

\section{Changes observed in relation to age:}

On association of age with response to the myth on cavities occurred only because of chocolates, a higher percentage of adolescents $(66 \%)$ believed it, while a majority of early (53\%) and middle adulthood (49\%) groups knew it was a myth $(\mathrm{p}=0.023)$ (Figure 2). Regarding the myth on longer brushing duration for brighter teeth, a higher percentage of respondents of late adulthood (68.5\%) and adolescents $(61.5 \%)$ believed it, while a majority of respondents in early adulthood (55.2\%) knew it was a myth $(\mathrm{p}=0.002)$ (Figure 3). Regarding the myth on chewing tobacco for better oral hygiene, a higher percentage of respondents of late adulthood (67.6\%) believed it, while a majority of respondents in early adulthood (58.9\%) knew it was a myth ( $\mathrm{p}=0.000)$ (Figure 4). Regarding the myth of not visiting a dentist without pain, a higher percentage of adolescents (68.8\%) believed it, while a majority of respondents in early (51.5\%) and middle adulthood 
$(52.35 \%)$ knew it was a myth $(\mathrm{p}=0.003)$

(Figure 5).

Changes observed in relation to educational status:

On association of gender with response to the myth on use of harder bristles for better cleaning, a higher percentage of respondents who completed only schoolings $(63.7 \%)$ believed it, while a majority of respondents who completed undergraduation $(52.3 \%)$ knew it was a myth $(\mathrm{p}=0.009)$

(Figure 6). Regarding the myth on chewing tobacco for better oral hygiene, a higher percentage of respondents who completed schooling (63.4\%) believed it, while a majority of respondents who completed undergraduation (56.5\%) and postgraduation $(46.82 \%)$ knew it was a myth $(\mathrm{p}=0.002)$

(Figure 7).

Changes observed in relation to employment status:

On association of employment status with response to the myth on having a little smoke or chewing tobacco at times wouldn't harm them, a higher percentage of unemployed respondents $(60.8 \%)$, while a majority of employed respondents (49.9\%) knew it was a myth $(p=0.023)$ (Figure 8).

Myths are common beliefs among people which started to take a serious place among the society by means of miscommunications. Myths are commonly prevalent in a population due to various reasons like poor education, cultural beliefs and social misconceptions. These myths get moved on to next generations creating unnecessary hoaxes. Such myths exist in the field of medicine and dentistry which requires serious attention among the general population. As dentists, it would be our duty to provide the correct knowledge based on advertisements and social media. To provide education, it is important to know about these myths and misconceptions prevalent in the population [1].

The sample of study population attending a dental institute would be apt for the study as many patients come from different parts of the city which helps to increase the external validity of the study thereby generalising the results to majority of the non-study population.

The questionnaire was designed based on most commonly prevalent myths among the general population. The questions were categorised under the 4 topics, i.e. dental caries, oral hygiene, oral cancer and general dental aspects. The questions were randomly chosen based on the researchers conversations with their day-to-day patients. Questioning the patients with common reasons for not visiting the dentist, their 
methods of maintaining oral hygiene, their cariogenic diet histories and their reasons for discontinuing smoking and alcoholic behaviour led to the common myths being used in the present set of population visiting the dental clinics. In order to avoid confusion in results, the questionnaire was framed in close-ended format with options of true and false.

\section{Myths regarding Dental Caries:}

Higher percentage of respondents believed that chocolate is the only cause of cavities. This can due to the common saying that sweetened food causes cavities and also health professionals have been stressing on avoiding chocolates. But dental caries is 'complex' or 'multi-factorial' thereby pertaining to multiple factors leading to cavities [24]. Most respondents believed that decay in primary teeth need not be treated as they may shed soon. They are still unaware of the shedding cycle of the primary teeth and the latter it is, the longer the duration of dental morbidity eventually. They need to be emphasized with the fact that different teeth take different time to shed thereby a different duration of eruption [25]. A higher percentage of respondents believed that to relieve tooth pain, it will be better to extract it rather than saving it. The awareness about treatment modalities was very low among patients which led to this misconception. This would also be due to the fact that multiple visits would be required for root canal treatment when compared with extraction. Many respondents believed that decay once treated, never recurs forever. The technique sensitive materials do matter a lot in the longevity of a restoration which could lead to secondary caries in the future without proper maintenance from the patient. Most respondents believed that there is no necessity for a crown after root canal treatment. There is lower awareness among people that the vitality is lost which makes the tooth more fragile [26]. Since the pain and discomfort is totally lost after the first visit, they believe it is completely treated and never return for the next appointment.

\section{Myths regarding Oral Hygiene:}

More number of respondents believed that brushing for a longer time with hard bristles can brighten and whiten the teeth much better. Overzealous brushing habits for longer duration would just abrade the enamel rather than protecting it [27]. An average number of respondents believed that brushing with salt, brick powder and charcoal can make their teeth brighter and whiter. These are highly abrasive materials which would make the tooth appear much better due to its abrasive action rather than protecting it. 
Similar results were obtained in another study by Saravanan et al. and Vignesh et al. $[28,29]$ Gums bleed due the fact of poor oral hygiene. Refraining from oral hygiene measures during such time would worsen the situation rather than making it better. Poor brushing habits is one among the many other reasons like gastrointestinal problem or pharyngeal problems which would lead to halitosis or bad breath. Even volatile foods could cause halitosis. There is lower awareness among general population [30, 31].

\section{Myths regarding Oral Cancer:}

Chewing tobacco for maintenance of better oral hygiene is similar to use of salt which eventually abrades rather than keeping it healthy. Smokeless tobacco, a single puff of smoke or drinking alcohol eventually leads to cancerous conditions and is not time dependent [29, 32]. The detrimental effects of tobacco outweighs its use as an abrasive. The carcinogenic exposure is similar to either ones but higher in smokeless tobacco [27, 33, 34]. Assuming that cancer is contagious is widespread fear but they are possibly mutations due to long term effects rather than a shorter duration of exposure from a person nearby [35]. There is ignorance regarding the susceptibility of different individuals to different diseases and unaware that most relatives of patients with oral cancers are at the same risk for cancer as the general population [36].

\section{Myths regarding General Dental Aspects:}

A higher percentage of the respondents believed that it is not required to visit a dentist unless a tooth pain occurs. Pain is the symptom which occurs only at the final stages of dental caries and not the initial symptom. So they don't realize the disease process undergoing within them.

Respondents also believe that it is better to avoid dental treatment during pregnancy. This is because the people generally believe that fetuses can get affected by the drugs and the treatment modality provided. But they are not aware that treatment has to be done when in emergency and other procedures can be done during the $2^{\text {nd }}$ trimester when organogenesis is complete [37]. There needs to be awareness that oral foci of infection when untreated can lead to preterm low birth weight of the child who is born. Few respondents believed that extracting any upper teeth may lead to loss of vision. This may be due to improper infra orbital nerve block followed which may cause slight blurring of vision until the effect of local anesthesia wears out [38]. The result is a contrast to the study done by $\mathrm{N}$. Saravanan and R. Thirineervannan where 
only $20 \%$ believed in the myth [29]. An extracted tooth needs a replacement soon with artificial ones to help in mastication, esthetics and other functions. Delay in doing so would lead to supra-eruptions and secondary reasons to extract the adjacent or opposing tooth as well. Professional scaling does not lead to sensitivity or mobility but the periodontal problem that occurred due to the formation of calculus had done these changes. The perception of patients is that all these started after the treatment rather than the disease as such.

Males would still believe that dental treatments could be avoided during pregnancy which tends to show their care towards their spouse's pregnancy condition rather than the dental problem. Adolescents believed that chocolates only caused cavities, longer brushing leads to brighter teeth and visiting a dentist was not required when there was no pain or symptoms. THis could be due to their lack of knowledge as the respondents in early and middle adulthood showed better knowledge by considering them myths. Respondents who completed only school showed poor knowledge compared to respondents who were graduates due to their lack in education. Also a higher percentage of unemployed respondents believed a little smoke wouldn't affect them which shows their neglect towards their health during difficult times [28, 39].

The advantages of the study is that there is high internal and moderate external validity due to the mixed samples in the study. However attributing it to the general population would still need a higher number of samples. Other limitations were most myths included in this study do not have established literature and it was framed from the beliefs commonly encountered in day-today practice. So an attempt was made to establish the causes for various myths by the authors without sufficient supporting literature. Our study is limited to a certain geographic locality which should be focused in the future studies.

A dental practitioner should provide health education and have a good rapport with the patient so that the patient openly tells about his beliefs which can be rectified along the chair side. Distribution of pamphlets or public health education or advertisements regarding the myths and facts on dentistry can provide a mass knowledge among the general population. The easiest way that can be done is to provide one-to-one conversation and clearing such myths among the patients as and when they step into our clinic. 
Table 1: Distribution of respondents based on age

\begin{tabular}{|c|c|}
\hline Age group & Percentage of respondents \\
\hline Adolescence & $\mathbf{2 1 . 8 \%}(\mathbf{n}=109)$ \\
\hline Early Adulthood & $\mathbf{2 6 . 8 \%}(\mathbf{n}=134)$ \\
\hline Middle Adulthood & $\mathbf{2 9 . 8 \% ( n = 1 4 9 )}$ \\
\hline Late Adulthood & $\mathbf{2 1 . 6 \%}(\mathbf{n}=108)$ \\
\hline
\end{tabular}

Table 2: Distribution of respondents based on gender

\begin{tabular}{|c|c|}
\hline Gender & Percentage of respondents \\
\hline Male & $\mathbf{5 3 . 2 \%}(\mathbf{n}=\mathbf{2 6 6})$ \\
\hline Female & $\mathbf{4 6 . 8 \%}(\mathbf{n}=\mathbf{2 3 4})$ \\
\hline
\end{tabular}

Table 3: Distribution of responses based on educational status

\begin{tabular}{|c|c|}
\hline Educational status & Percentage of respondents \\
\hline School & $\mathbf{2 6 . 8 \%}(\mathbf{n}=\mathbf{1 3 4})$ \\
\hline Undergraduate & $\mathbf{3 8 . 6 \%}(\mathbf{n}=193)$ \\
\hline Postgraduate & $\mathbf{3 4 . 6 \%}(\mathbf{n}=173)$ \\
\hline
\end{tabular}

Table 4: Distribution of respondents based on employment status

\begin{tabular}{|c|c|}
\hline Employment status & Percentage of respondents \\
\hline Unemployed & $\mathbf{3 4 . 2 \%}(\mathbf{n}=171)$ \\
\hline Employed & $\mathbf{6 5 . 8 \%}(\mathbf{n}=\mathbf{3 2 9})$ \\
\hline
\end{tabular}

Table 5: Responses given for questions related to myths regarding Dental Caries:

\begin{tabular}{|c|c|c|}
\hline Questions & True & False \\
\hline Chocolate is the only cause of cavities. & $54 \%$ & $46 \%$ \\
\hline Decay in milk teeth need not be treated as they are going to fall anyways. & $60.8 \%$ & $39.2 \%$ \\
\hline Any tooth pain due to decay, it's better to extract rather than saving it. & $\mathbf{6 1 . 4 \%}$ & $\mathbf{3 8 . 6 \%}$ \\
\hline Once a tooth is treated, the decay stops in that tooth. & $\mathbf{6 1 . 6 \%}$ & $\mathbf{3 8 . 4} \%$ \\
\hline There is no pain after Root Canal Treatment, so I don't need to place a crown. & $\mathbf{5 6 . 8 \%}$ & $\mathbf{4 3 . 2 \%}$ \\
\hline
\end{tabular}

Table 6: Responses given for questions related to myths regarding Oral Hygiene:

\begin{tabular}{|c|c|c|}
\hline Questions & True & False \\
\hline The longer you brush, the brighter the teeth become & $57 \%$ & $43 \%$ \\
\hline Using hard bristles will clean the teeth better and make it white & $56.2 \%$ & $43.8 \%$ \\
\hline Brushing your teeth using salt, whitens your teeth. & $68.2 \%$ & $31.8 \%$ \\
\hline Brick powder \& charcoal cleans your teeth better than a toothpaste. & $66.4 \%$ & $33.6 \%$ \\
\hline When gums bleed, it's better not to brush and floss your teeth. & $63.2 \%$ & $36.8 \%$ \\
\hline Poor brushing is the only cause of bad breath. & $54.6 \%$ & $45.4 \%$ \\
\hline
\end{tabular}

Table 7: Responses given for questions related to myths regarding Oral Cancer:

\begin{tabular}{|c|c|c|}
\hline \multicolumn{1}{|c|}{ Questions } & True & False \\
\hline Chewing tobacco helps in maintaining good oral hygiene. & $52.2 \%$ & $47.8 \%$ \\
\hline Smokeless tobacco is less harmful and a safe alternative to smoking. & $57.8 \%$ & $42.2 \%$ \\
\hline $\begin{array}{c}\text { Taking a puff of smoke or a chew of smokeless tobacco every now and then, } \\
\text { won't harm me. }\end{array}$ & $\mathbf{5 3 . 8 \%}$ & $\mathbf{4 6 . 2 \%}$ \\
\hline $\begin{array}{c}\text { Any relative of mine with an oral cancer, then I'm at higher risk of getting } \\
\text { cancer. }\end{array}$ & $\mathbf{6 1 . 6 \%}$ & $\mathbf{3 8 . 4 \%}$ \\
\hline $\begin{array}{c}\text { A friend of mine drinks, smokes and chews more than what I do, but still he } \\
\text { doesn't have oral cancer and neither will I. }\end{array}$ & $\mathbf{5 8 . 4 \%}$ & $\mathbf{4 1 . 6 \%}$ \\
\hline
\end{tabular}

Table 8: Responses given for questions related to myths regarding General Dental Aspects:

\begin{tabular}{|c|c|c|}
\hline Questions & True & False \\
\hline I don't have pain in my teeth, so it's not required to visit a dentist. & $54.6 \%$ & $45.4 \%$ \\
\hline It's better to avoid dental treatment during pregnancy. & $60.8 \%$ & $39.2 \%$ \\
\hline Extracting any upper teeth leads to loss of vision. & $60 \%$ & $40 \%$ \\
\hline Extracted teeth need no replacement with an artificial teeth. & $59.8 \%$ & $40.2 \%$ \\
\hline $\begin{array}{c}\text { Professional scaling leads to sensitivity, mobility in teeth and also creates a gap } \\
\text { between them. }\end{array}$ & $65 \%$ & $35 \%$ \\
\hline
\end{tabular}




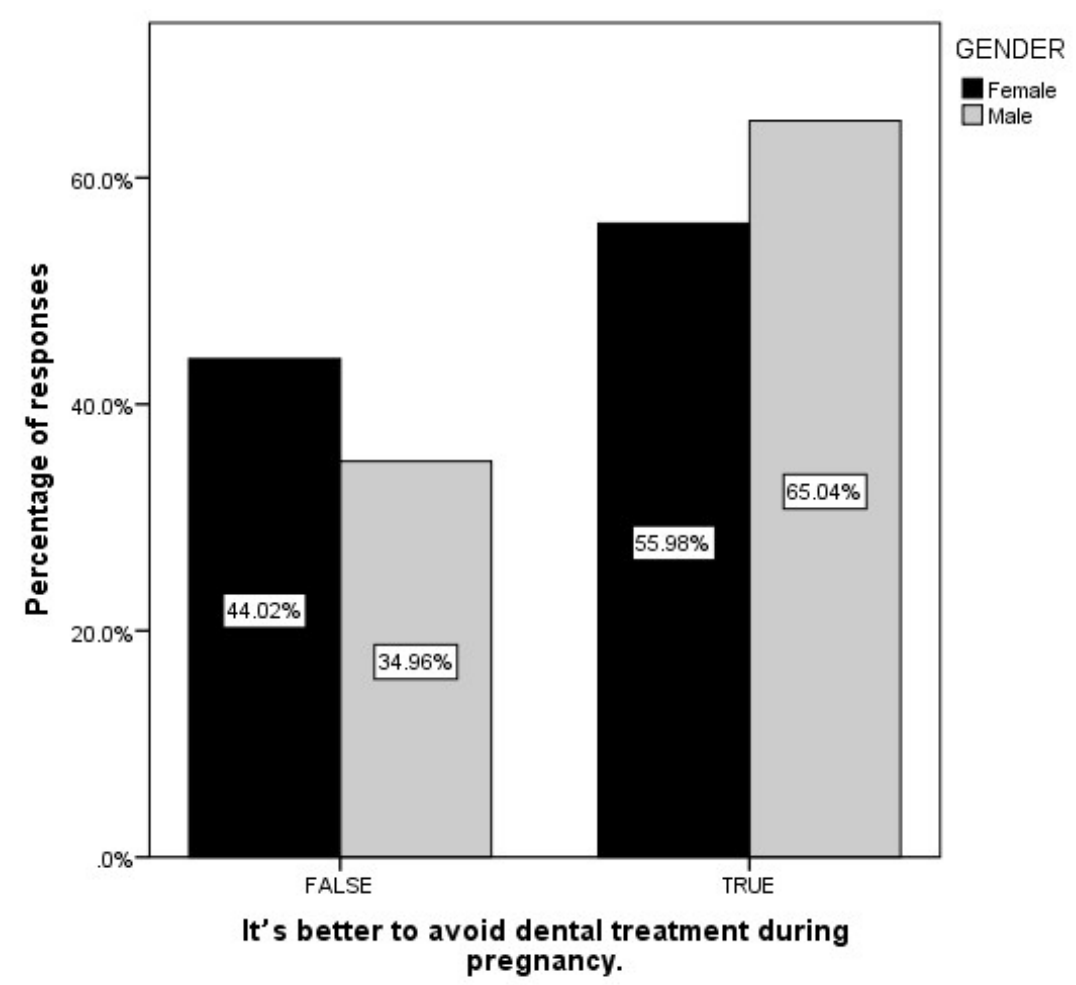

Figure 1: Bar graph showing association of gender with response to the myth on dental treatment during pregnancy. A higher percentage of males (65\%-grey) believed it, while the majority of females (44\%-black) knew it was a myth, which was statistically significant. (Chi-square test; $p=0.039$ )

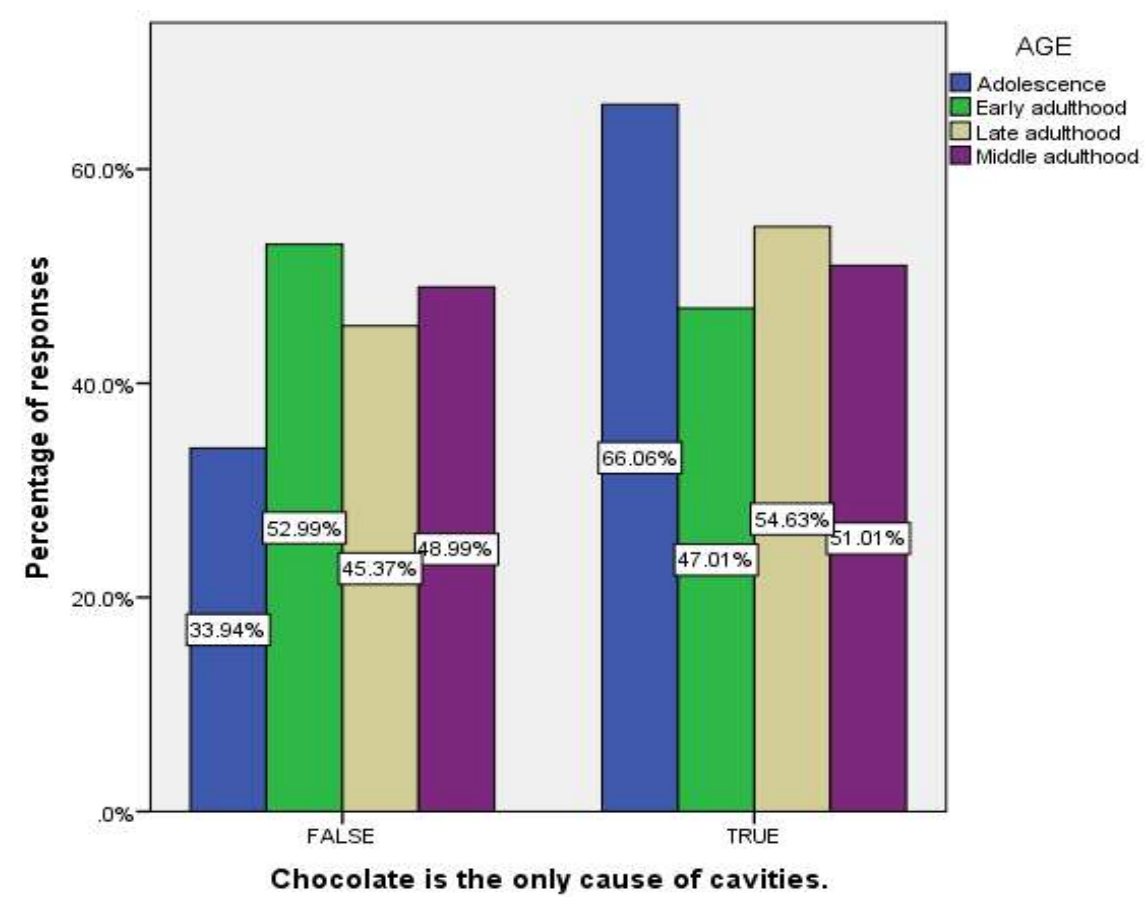

Figure 2: Bar graph showing association of age with response to the myth on cavities occurred only because of chocolates. A higher percentage of adolescents $(66 \%$ - blue) believed it, while a majority of early (53\% - green) and middle adulthood (49\% - violet) groups knew it was a myth, which was statistically significant. (Chi-square test; $p=0.023$ ) 


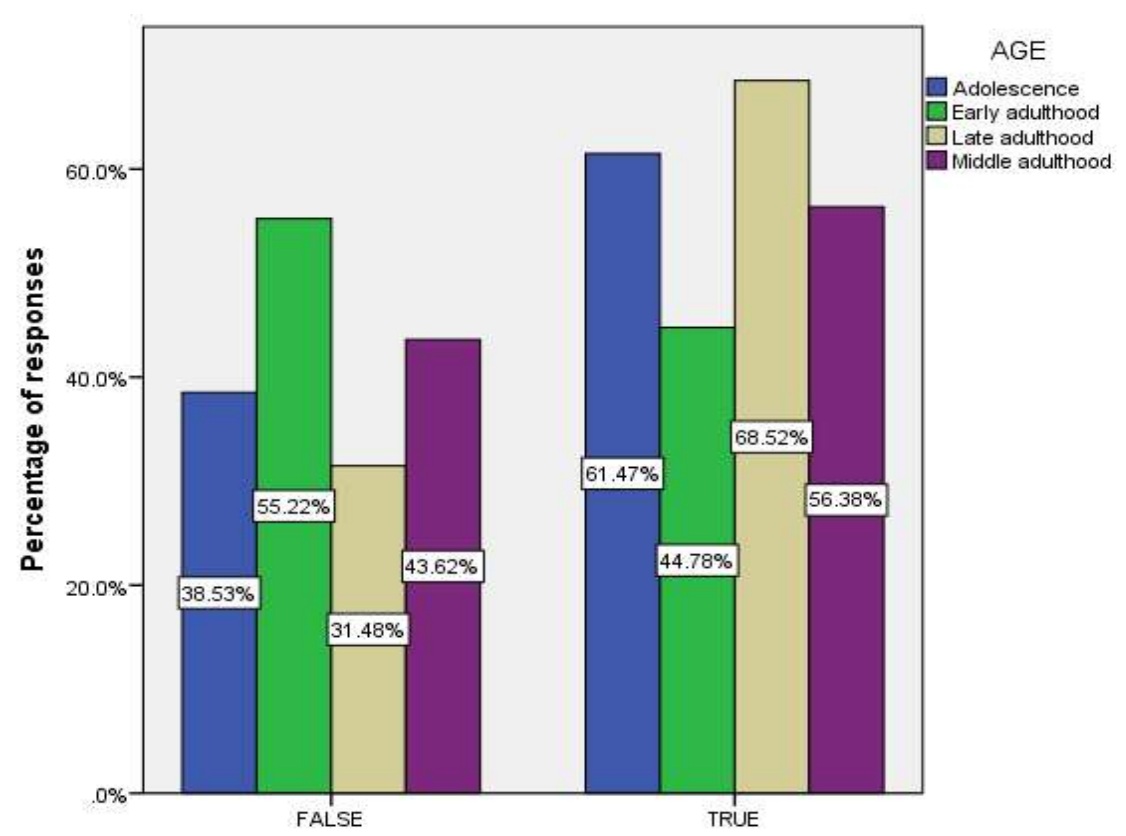

The longer you brush, the brighter the teeth become.

Figure 3: Bar graph showing association of age with response to the myth on longer brushing duration for brighter teeth. A higher percentage of respondents of late adulthood $(68.5 \%$ - beige) and adolescents $(61.5 \%$ - blue) believed it, while a majority of respondents in early adulthood $(55.2 \%$ - green) knew it was a myth, which was statistically significant. (Chi-

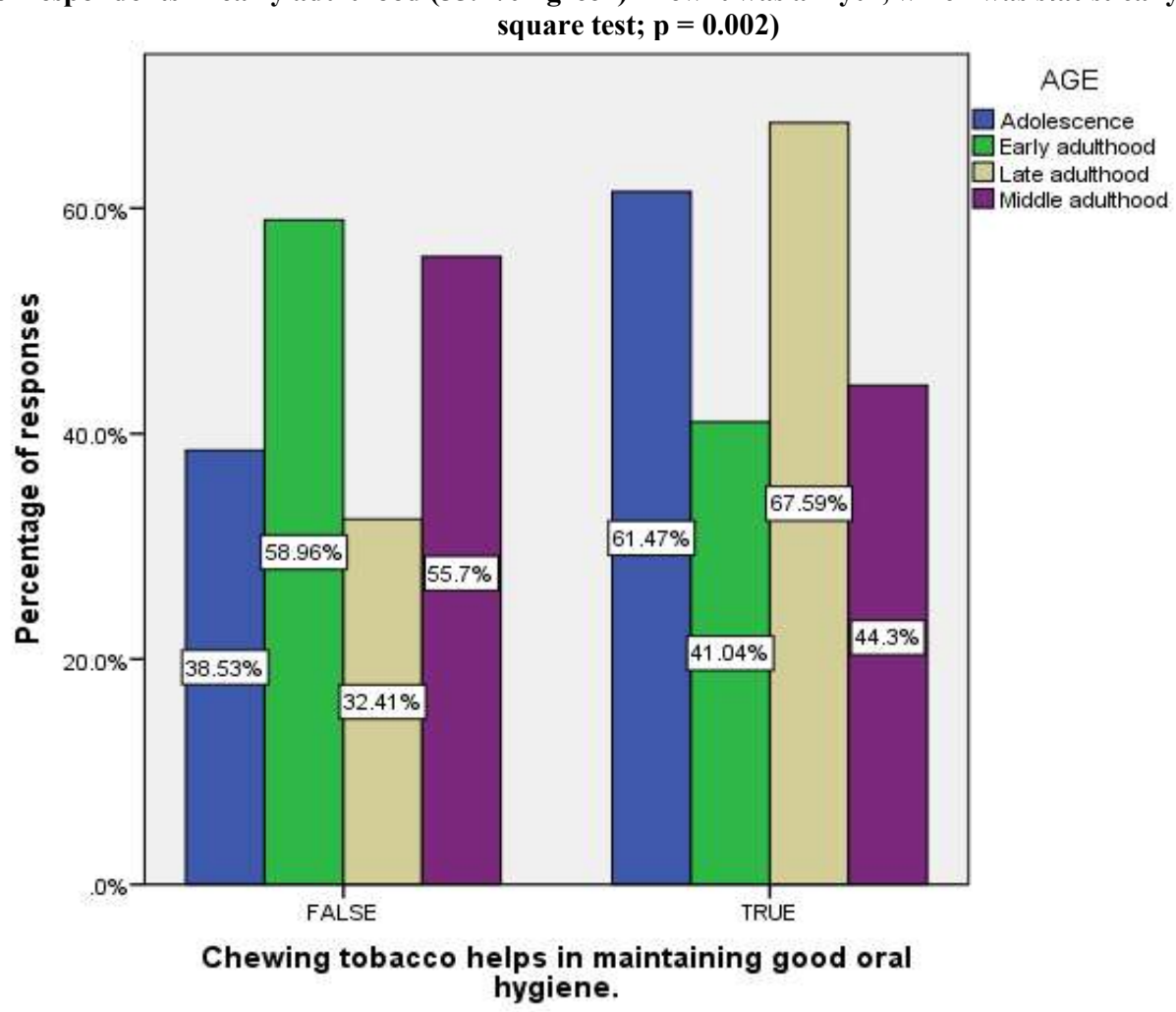

Figure 4: Bar graph showing association of age with response to the myth on chewing tobacco for better oral hygiene. A higher percentage of respondents of late adulthood $(67.6 \%$ - beige) believed it, while a majority of respondents in early adulthood (58.9\% - green) knew it was a myth, which was statistically significant. (Chi-square test; $\mathbf{p}=\mathbf{0 . 0 0 0})$ 


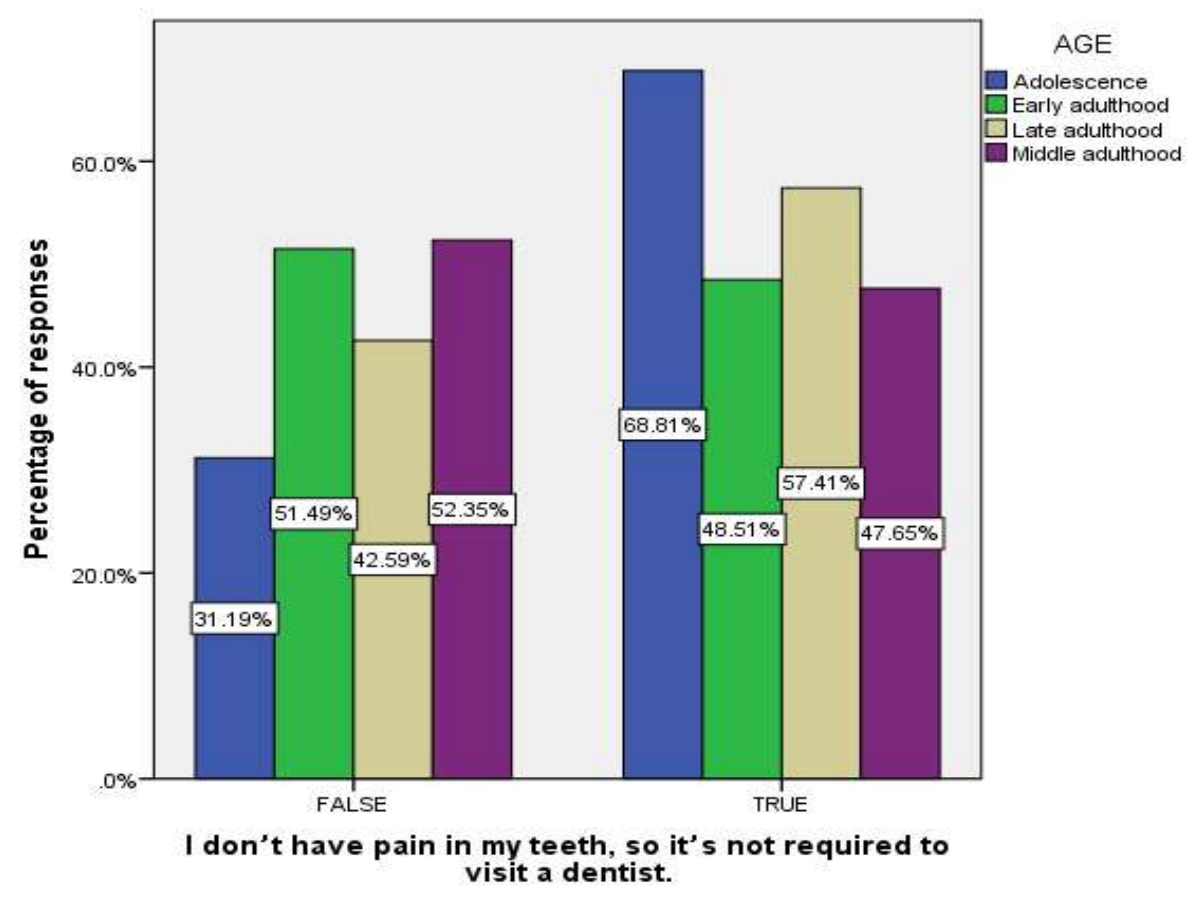

Figure 5: Bar graph showing association of age with response to the myth of not visiting a dentist without pain. A higher percentage of adolescents $(68.8 \%$ - blue) believed it, while a majority of respondents in early $(51.5 \%$ - green) and middle adulthood (52.35\% - violet) knew it was a myth, which was statistically significant. (Chi-square test; $p=0.003)$

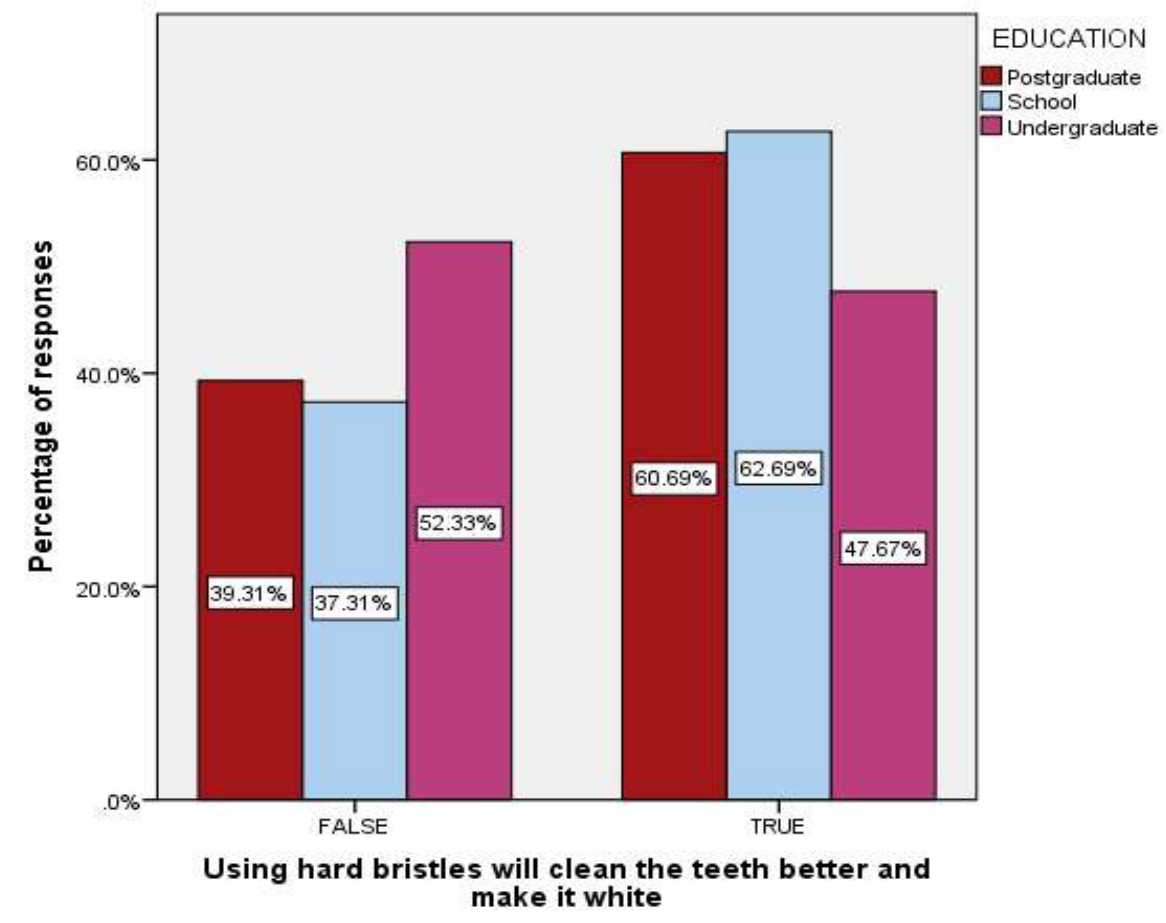

Figure 6: Bar graph showing association of educational status with response to the myth on use of harder bristles for better cleaning. A higher percentage of respondents who completed only schoolings $(63.7 \%$ - blue $)$ believed it, while a majority of respondents who completed undergraduation $(52.3 \%$ - pink) knew it was a myth, which was statistically significant. (Chi-square test; $p=0.009$ ) 


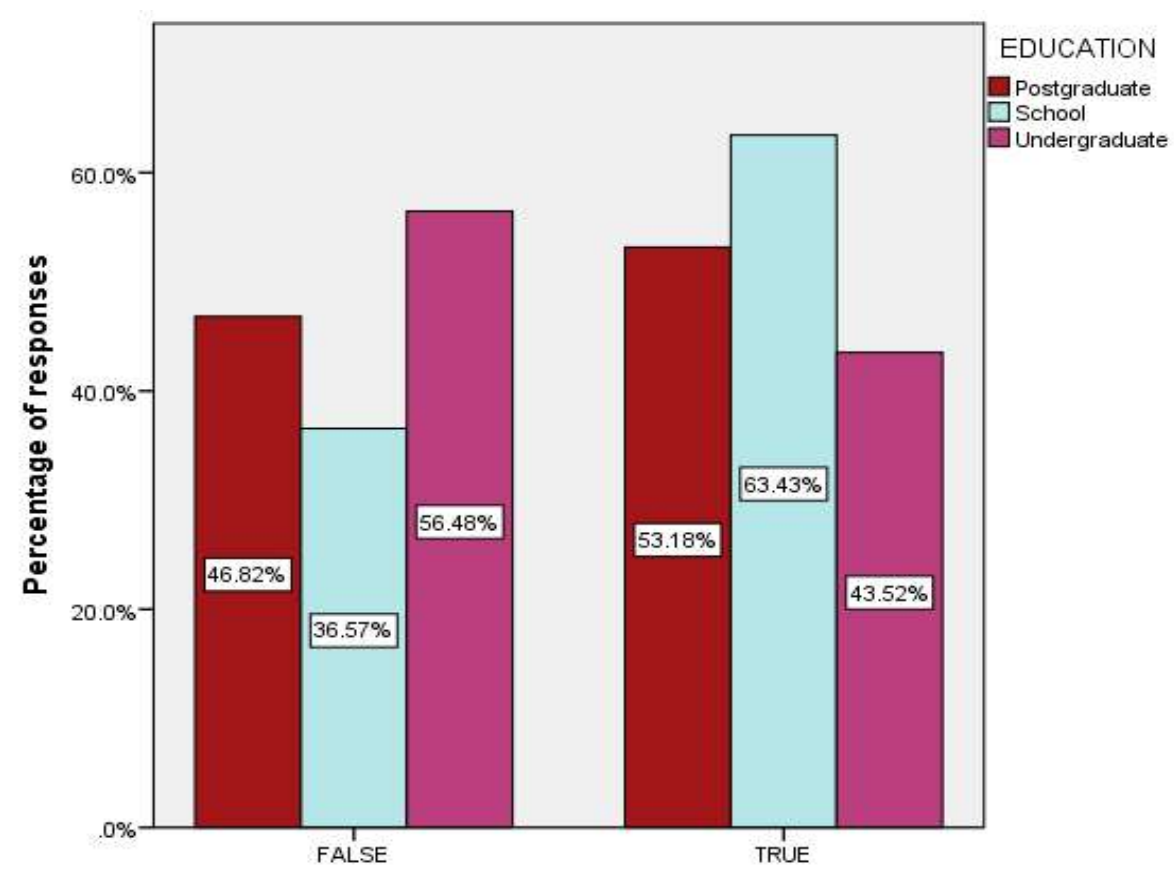

Chewing tobacco helps in maintaining good oral hygiene.

Figure 7: Bar graph showing association of educational status with response to the myth on chewing tobacco for better oral hygiene. A higher percentage of respondents who completed schooling $(63.4 \%$ - blue $)$ believed it, while a majority of respondents who completed undergraduation $(56.5 \%$ - pink) and postgraduation $(46.82 \%$ - maroon) knew it was a myth, which was statistically significant. (Chi-square test; $\mathbf{p}=\mathbf{0 . 0 0 2}$ )

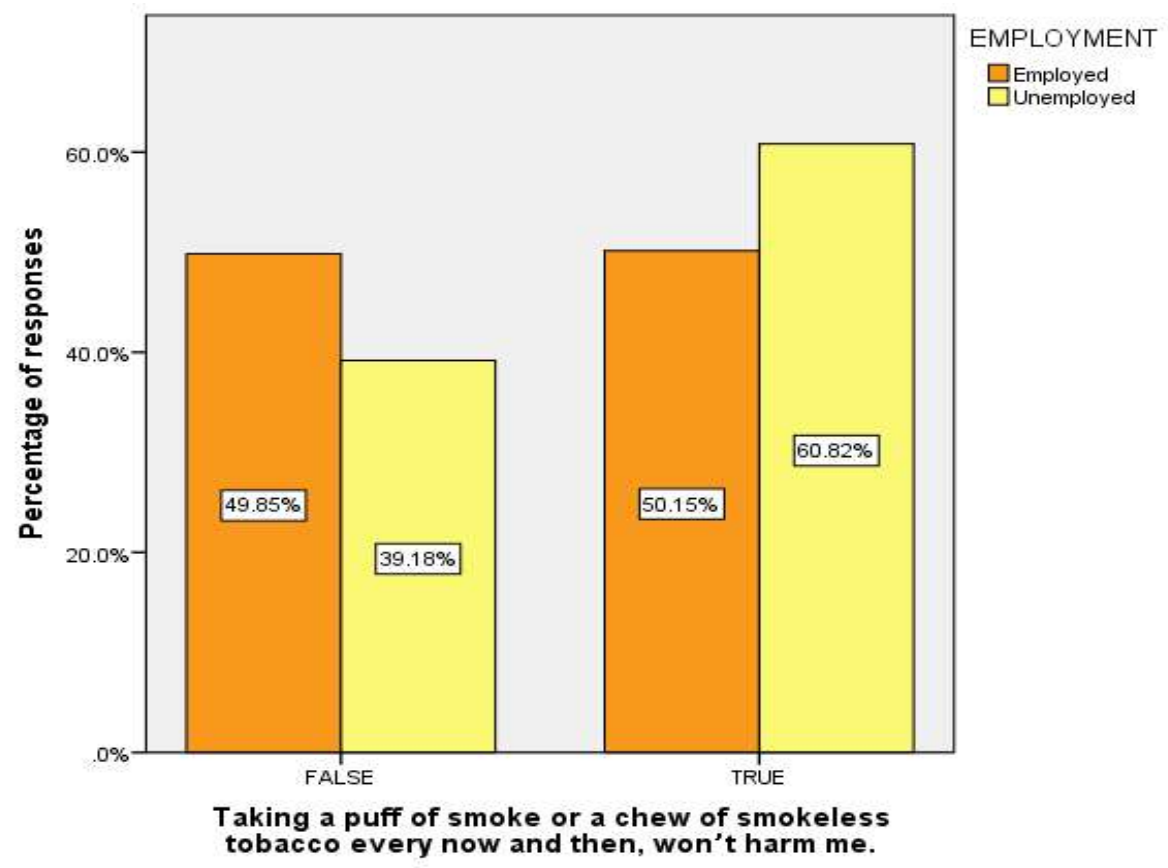

Figure 8: Bar graph showing association of employment status with response to the myth on having a little smoke or chewing tobacco at times wouldn't harm them. A higher percentage of unemployed respondents $(60.8 \%$ - yellow), while a majority of employed respondents $(49.9 \%$ - orange) $\mathrm{knew}$ it was a myth, which was statistically significant. (Chi-square test; $\mathbf{p}=\mathbf{0 . 0 2 3}$ ) 


\section{CONCLUSION}

Within the limitations of the present study, there is a higher percentage of the population who still believes in myths related to dentistry. The myths were more common among people who were not graduates and also belonging to late adulthood and even adolescents. So it is the prime duty of the dental practitioner to help the people learn via health care programs, mass media advertisements, educational pamphlets and even online courses.

\section{ACKNOWLEDGEMENT}

The authors acknowledge all the students who provided consent and spent their time on completing this survey.

\section{CONFLICTS OF INTEREST}

The authors of the study declare that there were no conflicts of interest.

\section{REFERENCES}

[1] Rai M, Kishore J. Myths about diabetes and its treatment in North Indian population. Int J Diabetes Dev Ctries. 2009 Jul;29(3):129-32.

[2] Heglund SP. Dental myths: a deterrent to dental care seeking behaviors in developing countries [Internet]. Vol. 1, Medical Case reports and Reviews. 2018. Available from:

http://dx.doi.org/10.15761/mcrr.1000
115

[3] Joshi S, Garg S, Dhindsa A, Jain N, Singh S. Prevalent Dental Myths and Practices in Indian Population- A Systematic Review [Internet]. Vol. 3, International Healthcare Research Journal. 2020. p. 316-26. Available from:

http://dx.doi.org/10.26440/ihrj/0310.0

1314

[4] Mythri H, Kumar RS. Perceived myths about oral health in India. Indian J Dent Res. 2015 May;26(3):333.

[5] Ravikumar D, N S, Ramakrishna M, Sharna N, Robindro W. Evaluation of McNamara's analysis in South Indian (Tamil Nadu) children between 8-12 years of age using lateral cephalograms. J Oral Biol Craniofac Res. 2019 Apr;9(2):193-7.

[6] Ravikumar D, Gurunathan D, Gayathri R, Priya V, Geetha RV. DNA profiling of Streptococcus mutans in children with and without black tooth stains: A polymerase chain reaction analysis. Dent Res J . 2018;15(5):334.

[7] Ravikumar D, Jeevanandan G, Subramanian EMG. Evaluation of knowledge among general dentists in 
treatment of traumatic injuries in primary teeth: A cross-sectional questionnaire study. Eur J Dent. 2017 Apr;11(2):232-7.

[8] Ravindra V, Rekha V, Annamalai S, Sharmin D, Norouzi-Baghkomeh P. A comparative evaluation between dermatoglyphic patterns and different terminal planes in primary dentition. $\mathrm{J}$ Clin Exp Dent. 2018 Dec;10(12):e1149-54.

[9] Ravindra V, Rekha CV, Annamalai S, Sharmin DD, Norouzi-Baghkomeh P. A comparative evaluation between cheiloscopic patterns and the permanent molar relationships to predict the future malocclusions. $\mathrm{J}$ Clin Exp Dent. 2019 Jun;11(6):e5537.

[10] Govindaraju L, Jeevanandan G, Subramanian EMG. Comparison of quality of obturation and instrumentation time using hand files and two rotary file systems in primary molars: A single-blinded randomized controlled trial. Eur J Dent. 2017 Jul;11(3):376-9.

[11] Govindaraju L, Jeevanandan G, Subramanian EMG. Knowledge and practice of rotary instrumentation in primary teeth among indian dentists:
A questionnaire survey. J Int Oral Health. 2017;9(2):45.

[12] Nair M, Jeevanandan G, Vignesh R, Emg S. Comparative evaluation of post-operative pain after pulpectomy with k-files, kedo-s files and mtwo files in deciduous molars -a randomized clinical trial. BDS. 2018 Oct 24;21(4):411.

[13] Jeevanandan G, Ganesh S, Arthilakshmi. Kedo file system for root canal preparation in primary teeth. Indian J Dent Res. 2019 Jul;30(4):622-4.

[14] Panchal V, Jeevanandan G, Subramanian E. Comparison of instrumentation time and obturation quality between hand $\mathrm{K}$-file, $\mathrm{H}$-files, and rotary Kedo-S in root canal treatment of primary teeth: A randomized controlled trial. J Indian Soc Pedod Prev Dent. 2019 Jan;37(1):75-9.

[15] Subramanyam D, Gurunathan D, Gaayathri R, Vishnu Priya V. Comparative evaluation of salivary malondialdehyde levels as a marker of lipid peroxidation in early childhood caries. Eur J Dent. 2018 Jan;12(1):67-70.

[16] Vignesh R, Sharmin D, Rekha CV, 
Annamalai S, Baghkomeh PN.

Management of Complicated

Crown-Root Fracture by Extra-Oral

Fragment Reattachment and

Intentional Reimplantation with 2

Years Review. Contemp Clin Dent.

2019 Apr;10(2):397-401.

[17] Ramadurai N, Gurunathan D, Samuel AV, Subramanian E, Rodrigues SJL. Effectiveness of 2\% Articaine as an anesthetic agent in children: randomized controlled trial. Clin Oral Investig. 2019 Sep;23(9):3543-50.

[18] Panchal V, Gurunathan D, Shanmugaavel AK. Smartphone application as an aid in determination of caries risk and prevention: A pilot study. Eur J Dent. 2017 Oct;11(4):469-74.

[19] Panchal V, Jeevanandan G, Subramanian EMG. Comparison of post-operative pain after root canal instrumentation with hand K-files, $\mathrm{H}$-files and rotary Kedo-S files in primary teeth: a randomised clinical trial. Eur Arch Paediatr Dent. 2019 Oct;20(5):467-72.

[20] Jeevanandan G, Govindaraju L. Clinical comparison of Kedo-S paediatric rotary files vs manual instrumentation for root canal preparation in primary molars: a double blinded randomised clinical trial. Eur Arch Paediatr Dent. 2018 Aug;19(4):273-8.

[21] Samuel SR, Acharya S, Rao JC. School Interventions-based Prevention of Early-Childhood Caries among 3-5-year-old children from very low socioeconomic status: Two-year randomized trial. J Public Health Dent. 2020 Jan;80(1):51-60.

[22] Ramakrishnan M, Dhanalakshmi R, Subramanian EMG. Survival rate of different fixed posterior space maintainers used in Paediatric Dentistry - A systematic review. Saudi Dent J. 2019 Apr;31(2):16572.

[23] Vishnu Prasad S, Kumar M, Ramakrishnan M, Ravikumar D. Report on oral health status and treatment needs of 5-15 years old children with sensory deficits in Chennai, India. Spec Care Dentist. 2018 Jan;38(1):58-9.

[24] Fejerskov O. Changing Paradigms in Concepts on Dental Caries: Consequences for Oral Health Care [Internet]. Vol. 38, Caries Research. 
2004. p. 182-91. Available from: http://dx.doi.org/10.1159/00007775 3

[25] Haralur SB, Al-Faifi AH. Use of $\mathrm{CAD} / \mathrm{CAM}$ in Esthetic Restoration of Badly Decayed Tooth [Internet]. Vol. 2012, Case Reports in Dentistry. 2012. p. 1-3. Available from:

http://dx.doi.org/10.1155/2012/6082 32

[26] Randow K, Glantz PO. On cantilever loading of vital and nonvital teeth. An experimental clinical study. Acta Odontol Scand. 1986 Oct;44(5):271-7.

[27] Grippo JO, Simring M, Schreiner S. Attrition, abrasion, corrosion and abfraction revisited: a new perspective on tooth surface lesions. J Am Dent Assoc. 2004 Aug;135(8):1109-18; quiz 1163-5.

[28] Vignesh R, Priyadarshni I. Assessment of the prevalence of myths regarding oral health among general population in Maduravoyal, Chennai [Internet]. Vol. 2, Journal of Education and Ethics in Dentistry. 2012. p. 85. Available from:

http://dx.doi.org/10.4103/0974-
7761.121262

[29] Saravanan N, Thiruneervannan R. Assessment of dental myths among dental patients in Salem City. Journal of Indian Association of Public Health Dentistry. 2011 Oct 1;9(18):359.

[30] Porter SR, Scully C. Oral malodour (halitosis) [Internet]. Vol. 333, BMJ. 2006. p. 632-5. Available from: http://dx.doi.org/10.1136/bmj.38954 $.631968 . \mathrm{ae}$

[31] Chhabra N, Chhabra A. Parental knowledge, attitudes and cultural beliefs regarding oral health and dental care of preschool children in an Indian population: a quantitative study. Eur Arch Paediatr Dent. 2012 Apr;13(2):76-82.

[32] Jhanjee S, Lal R, Mishra A, Yadav D. Tobacco use and dental myths In India: need for specific intervention. Gerodontology. 2016 Dec;33(4):573-4.

[33] Russell MA, Jarvis MJ, West RJ, Feyerabend C. Buccal absorption of nicotine from smokeless tobacco sachets. Lancet. 1985 Dec 14;2(8468):1370.

[34] Benowitz NL, Porchet H, Sheiner L, Jacob P. Nicotine absorption and 
cardiovascular effects with smokeless tobacco use: Comparison with cigarettes and nicotine gum [Internet]. Vol. 44, Clinical Pharmacology and Therapeutics. 1988. p. 23-8. Available from: http://dx.doi.org/10.1038/clpt.1988. 107

[35] Singh SV, Akbar Z, Tripathi A, Chandra S, Tripathi A. Dental myths, oral hygiene methods and nicotine habits in an ageing rural population: an Indian study. Indian J Dent Res. 2013 Mar;24(2):242-4.

[36] Moutou C, Le Bihan C, Chompret A, Poisson N, Brugières L, Bressac $\mathrm{B}$, et al. Genetic transmission of susceptibility to cancer in families of children with soft tissue sarcomas [Internet]. Vol. 78, Cancer. 1996. p.
1483-91. Available from: http://dx.doi.org/10.1002/(sici)10970142(19961001)78:7<1483::aidcncr16>3.0.co; $2-\mathrm{w}$

[37] Silk H, Douglass AB, Douglass JM, Silk L. Oral health during pregnancy. Am Fam Physician. 2008 Apr 15;77(8):1139-44.

[38] Newadkar UR, Chaudhari L, Khalekar Y. Myths and misconceptions in general public toward ocular complications followed by the removal of upper teeth. J Family Med Prim Care. 2016 Oct;5(4):785-8.

[39] Pebble M. Debunking dental myths [Internet]. Vol. 14, Dental Nursing. 2018. p. 508-9. Available from: http://dx.doi.org/10.12968/denn.201 8.14.10.508 